\title{
PRESIDENT'S COLUMN
}

\section{Oral Health Integration: A Call to Action}

Stephanie A. Gill, MD, MPH; Beat D. Steiner, MD, MPH

(Fam Med. 2018;50(8):637-9.)

doi: 10.22454/FamMed.2018.988346

$\mathbf{M}$ y last column focused on patients with serious mental illness. This column will focus on oral health. Why this focus on clinical topics, and why am I again cowriting the presidential column with a colleague? What both of these clinical topics share in common is how poorly they are integrated into the core curriculum of family medicine. Patients with serious mental illness suffer profoundly and as I described in my last column, we are missing opportunities to teach our learners how to integrate care for this vulnerable group of patients. Patients with poor oral health also frequently come to our offices in severe distress, and our learners are puzzled about the artificial separation between oral health and the rest of the body. This column is a call to action to better integrate oral health care into our curriculum. I am writing this column with the leader of the STFM Collaborative on Oral Health to draw attention to the powerful role of collaboratives in our organization. Stephanie Gill has used the Collaborative on Oral Health as an effective advocacy tool to remind us of the importance of oral health in the care of our patients.

Key linkages have been found between many systemic diseases and oral health, both in their manifestation and treatment. ${ }^{1-6}$ Poor oral health can also negatively impact quality of life and cause significant pain and disability. ${ }^{7-9}$ Unfortunately, oral health remains an area of profound unmet need for many of our patients. More than a third of adults ages 2044 years, and nearly one in five children ages 5-19 years had untreated dental caries during 2011-2014. ${ }^{10}$ These statistics are even worse for racial and ethnic subpopulations.
While many of these patients do not have a regular dentist, they do see a family physician. Brief, focused oral examinations by the family physician can lead to timely management of these conditions, better systemic control of the conditions affected by them, and improved quality of life for our patients. Family physicians can also apply topical fluoride varnish for children under 6 years of age in less than a minute (Level B US Preventive Services Task Force recommendation). ${ }^{11}$

\section{Improving Oral Health Education for Future Family Physicians}

We clearly must do more to integrate medical and oral health care. One way to start is to ensure family physicians in training learn to take just as much responsibility in caring for patients' oral health as they do for the rest of the body.

In June, Family Medicine published "An Update of Oral Health Curricula in US Family Medicine Residency Programs" by Silk et al, ${ }^{12}$ who found that since 2011, more family medicine residency program directors feel that oral health should be addressed by physicians. But fewer programs are teaching oral health, and in programs still providing training in oral health care, fewer hours overall are dedicated to oral health education. In fact, one-fifth of the programs that responded have no oral health curriculum, and less than $20 \%$ of program directors indicated satisfaction with their trainees' level of competency in oral health. Silk et al also noted that the decrease in overall teaching hours dedicated to oral health coincides with the time frame that the ACGME cut oral health as a requirement in family medicine. 


\section{What Can We Do?}

The good news is that a variety of resources are available to promote integration of oral health into primary care and to prepare existing and future family physicians to assess the oral health status of our patients.

One valuable resource is the STFM Smiles for Life national oral health curriculum available at www.smilesforlifeoralhealth.org. The Smiles for Life website offers guidance for teaching the oral health curriculum as well as online learning modules and other resources, such as mobile apps, interactive games, clinical guidelines, and patient handouts. Family medicine residents can easily complete modules that correspond to their clinical rotations as they progress through their residency training. For instance, an $\mathrm{OB} / \mathrm{GYN}$ rotation is an excellent occasion for residents to complete the "Pregnancy and Women's Oral Health" module. The "Geriatric Oral Health" module can easily complement a geriatrics rotation, and residents could complete the "Acute Dental Problems" module during outpatient, urgent care, or emergency medicine rotations. Residents also should complete the "Caries Risk Assessment, Fluoride Varnish and Counseling" module because completing it is a requirement to receive reimbursement for in-office topical fluoride varnish application in many states.

Guidance also is available from the Association of American Medical Colleges (AAMC) on integrating oral health into the medical school curriculum. The "Contemporary Issues in Medicine: Oral Health Education for Medical and Dental Schools" AAMC report outlined oral health learning objectives, competencies, and educational strategies. ${ }^{13}$ Adding oral health into the medical school curriculum can be done in many ways and affords opportunities for innovative teaching and learning experiences, such as interprofessional collaborations, establishment of formal teaching relationships with local dental professionals, community outreach partnerships, and value-added clinical activities.

A variety of resources are available to facilitate practice redesign related to oral health integration. The Safety Net Medical Home Initiative (http://www.safetynetmedicalhome. org/change-concepts/organized-evidence-basedcare/oral-health) has published organized, evidence-based materials to assist in the integration of oral health into the primary care setting. Through this initiative, Qualis Health published a white paper in 2015 that presents an oral health delivery framework ${ }^{15}$ and a companion implementation guide in $2016 .^{15}$ The oral health delivery framework includes five actions primary care teams can take to protect and promote oral health: (1) Ask patients about oral health symptoms and risk factors, (2) Look for signs of oral health issues, (3) Decide on the most appropriate response, (4) Act by providing patient education and any needed referrals, (5) Document what you found and did to facilitate follow-up and quality improvement. The Health Resources and Services Administration (HRSA) also has a web page of resources devoted to oral health and primary care integration at https://bphc.hrsa.gov/qualityimprovement/clinicalquality/oralhealth/.

Finally, STFM members can join the STFM Oral Health Collaborative to link with others interested in promoting and championing oral health education within their institutions. Other STFM collaboratives should also explore how they can promote oral health education within their own areas of interest. For example, there is a "Global Oral Health" module in the Smiles for Life curriculum, and the Smiles for Life website includes an excellent selection of recommended links, such as HIVdent (www.hivdent.org), which provides extensive pictorial and print resources on the oral health care of patients with HIV/AIDS.

Our call to action is clear. Our patients need us to take as much interest in their mouths as we do their hearts. Taking a minute or two to ask our patients about their oral health, competently examining their mouths, applying fluoride varnish to our pediatric patients' teeth, and referring to a dental home when appropriate, can prevent needless morbidity and mortality. As teachers of family medicine we need to equip our learners with these basic skills.

CORRESPONDENCE: Address correspondence to Dr Steiner, University of North Carolina School of Medicine FMR, 590 Manning Dr, Campus Box 7595, Chapel Hill, NC 27599. 919-966-3711. Fax: 919-966-6125. beat_steiner@med.unc.edu.

\section{References}

1. Otomo-Corgel J, Pucher JJ, Rethman MP, Reynolds MA State of the science: chronic periodontitis and systemic health. J Evid Based Dent Pract. 2012;12(3)(suppl):20-28.

2. Peter KP, Mute BR, Doiphode SS, Bardapurkar SJ, Borkar MS, Raje DV. Association between periodontal disease and chronic obstructive pulmonary disease: a reality or just a dogma? J Periodontol. 2013;84(12):1717-1723.

3. Rautemaa R, Lauhio A, Cullinan MP, Seymour GJ. Ora infections and systemic disease--an emerging problem in medicine. Clin Microbiol Infect. 2007;13(11):1041-1047.

4. Palmer SC, Ruospo M, Wong G, et al; ORALD Investigators. Patterns of oral disease in adults with chronic kidney disease treated with hemodialysis. Nephrol Dial Transplant. 2016;31(10):1647-1653 
5. Offenbacher S, Barros SP, Altarawneh S, Beck JD, Loewy ZG. Impact of tooth loss on oral and systemic health. Gen Dent. 2012;60(6):494-500.

6. Javed F, Warnakulasuriya S. Is there a relationship between periodontal disease and oral cancer? A systematic review of currently available evidence. Crit Rev Oncol Hematol. 2016;97:197-205.

7. Ng SK, Leung WK. Oral health-related quality of life and periodontal status. Community Dent Oral Epidemiol. 2006;34(2):114-122.

8. Kim HY, Jang MS, Chung CP, et al. Chewing function impacts oral health-related quality of life among institutionalized and community-dwelling Korean elders. Community Dent Oral Epidemiol. 2009;37(5):468-476.

9. Jensen PM, Saunders RL, Thierer T, Friedman B. Factors associated with oral health-related quality of life in community-dwelling elderly persons with disabilities. J Am Geriatr Soc. 2008;56(4):711-717.

10. National Center for Health Statistics. Health, United States, 2016: With Chartbook on Long-Term Trends in Health. Hyattsville, MD: National Center for Health Statistics; 2017.

11. Moyer VA; US Preventive Services Task Force. Prevention of dental caries in children from birth through age 5 years: US Preventive Services Task Force recommendation statement. Pediatrics. 2014;133(6):1102-1111.
12. Silk H, Savageau JA, Sullivan K, Sawosik G, Wang M. An Update of Oral Health Curricula in US Family Medicine Residency Programs. Fam Med. 2018;50(6):437-443.

13. Association of American Medical Colleges. Report IX: Contemporary Issues in Medicine: Oral Health Education for Medical and Dental Schools. Washington, DC: AAMC; 2008.

14. Hummel J, Phillips K, Holt B, Hayes C. Oral Health: An Essential Component of Primary Care. Seattle, WA: Qualis Health; 2015.

15. Safety Net Medical Home Initiative, Hummel J, Phillips K, Holt B, Virden M. Organized, Evidence-Based Care Supplement: Oral Health Integration. Seattle, WA: Qualis Health; 2016. 